\title{
Emigración forzada de familias por la violencia en el sur de Sinaloa: experiencias trágicas y complejas*
}

\section{Forced Emigration of Families due to Violence in Southern Sinaloa: Tragic and Complex Experiences}

\author{
Roberto Carlos López López \\ (D) https://orcid.org/0000-0003-0822-8504 \\ Facultad de Ciencias Sociales \\ Universidad Autónoma de Sinaloa, México \\ robertolopez@uas.edu.mx
}

Resumen: Este trabajo estudia la migración forzada por la violencia en México, en particular en Sinaloa, en el contexto de la "guerra contra el narcotráfico". El objetivo general del artículo es analizar el proceso de la emigración forzada por violencia y la integración en la sociedad receptora, no como etapas separadas, sino como parte de un proceso continuo de la migración y de las experiencias de las familias. Y lo que interesa es conocer esa experiencia del proceso, desde la emigración, el desplazamiento, hasta la integración. Estas experiencias están marcadas por la tragedia, la vulnerabilidad social y por el miedo. Pero, son las redes sociales y familiares las que han permitido la sobrevivencia de las familias, principalmente. El retorno definitivo parece lejano,

* Este artículo es resultado de la Estancia Académica Posdoctoral Primer año 2018, patrocinada por el ConACYT en la Facultad de Ciencias Sociales de la Universidad Autónoma de Sinaloa.

cómo citar: López López, R. C. (2020). Emigración forzada de familias por la violencia en el sur de Sinaloa: experiencias trágicas y complejas. Secuencia (108), e1727. DoI: https://doi.org/10.18234/secuencia.v0i108.1727

c) 98

Esta obra está protegida bajo una Licencia Creative Commons Atribución-NoComercial 4.0 Internacional. 
porque sus pueblos fueron trastocados y no se les han garantizado las condiciones de seguridad ni restablecido la forma de vida de sus comunidades.

Palabras clave: emigración forzada; violencia; experiencias; integración; Sinaloa.

Abstract: This article explores forced migration due to violence in Mexico, particularly in Sinaloa in the context of the "war on drugs". The overarching aim of the article is to analyze forced emigration due to violence and integration in the receiving society, not as separate stages, but rather as part of a continuous process of migration, and the experiences of families. It explores this process from emigration through displacement to integration, marked by tragedy, social vulnerability, and fear. The article finds that it is social and family networks that have permitted the survival of families. A permanent return seems unlikely, however, because their towns have been disrupted and their conditions of safety have not been guaranteed nor has the way of life in their communities been restored.

Key words: forced emigration; violence; experiences; integration; Sinaloa.

Recibido: 14 de marzo de 2019 Aceptado: 23 de octubre de 2019

Publicado: 24 de agosto de 2020

\section{INTRODUCCIÓN}

Z $\mathrm{n}$ diciembre de 2006, al inicio de su administración como presidente de la _república, Felipe Calderón Hinojosa emprendió la llamada "guerra contra el narcotráfico”, con lo que comenzó una de las etapas más violentas que ha vivido México. Así, los grupos del crimen organizado han usado métodos violentos para el control territorial de cultivos de estupefacientes y narcolaboratorios, en las rutas de tráfico, y para neutralizar a las organizaciones contrarias. Los narcotraficantes y otros grupos criminales han sido los responsables de los miles de muertes de civiles, secuestros, amenazas y extorsiones, entre otros delitos que han aterrorizado a las poblaciones locales y que los ha forzado a la migración. El país parece estar en una crisis humanitaria encubierta, 
porque una parte de la población, principalmente de comunidades rurales, han sido expulsadas por los cárteles de la droga.

De acuerdo con Albuja et al. (2014), el Internal Displacement Monitoring Centre (IDMC) y el Norwegian Refugee Council (NRC) estimaron que, hasta 2013, había en México entre 160 y 180000 desplazados a causa de la violencia criminal. Y según Desai, Ginnetti, Sémnani y Ansellini (2018), el IDMC y el NRC aseguraron que, hasta 2017, había más de 345000 mexicanos en situación de desplazamiento forzado por violencia y conflictos.

En Sinaloa, a partir de la "guerra contra el narcotráfico", la violencia ya generalizada se hizo más extrema y cotidiana (López, 2017) respecto a las décadas anteriores (Lizárraga, 2004), con costos sociales evidentes que alcanzaron a todos los sectores sociales. Esta violencia mucho más cruenta se hizo más notoria a partir del conflicto surgido en 2008, tras la ruptura entre el cártel de Sinaloa y el grupo criminal de los Beltrán Leyva (Gutiérrez, 2018), así como por el combate de las fuerzas policiales y militares en contra de ellos (Meza, Cuamea y Brito, 2014); lo que ha provocado la migración forzada, principalmente en la Sierra Madre Occidental y en algunas zonas rurales del estado.

De acuerdo con las solicitudes de información (con folios 00234413, 00235014 y 01205618) y con una revisión de la prensa local -Noroeste, Riodoce, El Debate y El Sol de Mazatlán-, durante el periodo 2006-2018 por lo menos trece de 18 municipios de Sinaloa, principalmente los serranos, han tenido casos de migración forzada por la violencia y la inseguridad. En su mayoría, las familias o personas se han desplazado a las principales ciudades del estado para resguardarse y buscar ayuda. Cabe señalar que existe una dificultad metodológica por parte de las autoridades para cuantificar a estas personas, lo que dificulta ver con claridad la magnitud del fenómeno.

El objetivo de este artículo es analizar el proceso de esta emigración forzada por violencia y la integración de los desplazados en la sociedad receptora, no como etapas separadas, sino como parte de un proceso continuo de la migración y de las experiencias de las familias. Y lo que interesa es conocer esa experiencia del proceso, desde la emigración, el desplazamiento, hasta la integración.

El presente texto se estructura en cuatro partes: en la primera, se exponen los conceptos que guían esta investigación, basados en la sociología y la antropología, para enseguida presentar la metodología que se llevó a cabo. En la segunda parte se describe la migración forzada por la violencia en México, señalando las causas, los estados afectados, las estimaciones y los patrones. 
En la tercera parte se presenta el caso de la migración forzada por la violencia en Sinaloa; las causas, motivos, las experiencias de las familias desde el desplazamiento y las estrategias de supervivencia que implementaron, su integración en la sociedad receptora, la utilización de las redes sociales y familiares como estrategias de su permanencia en la ciudad, así como el (no)retorno. Finalmente, concluimos que la experiencia del proceso migratorio estuvo marcada por la tragedia, la vulnerabilidad social y el miedo. Asimismo, que la integración de las familias a la ciudad implicó diferentes maneras de aculturación y distintos grados de integración, en donde la utilización de las redes sociales y familiares les permitió sobrevivir, una mayor posibilidad de superar algunas necesidades o bien mejorar sus condiciones de vida.

\section{MARCO CONCEPTUAL}

La primera definición de Personas Desplazadas Internamente, basada en los Principios Rectores de los desplazamientos internos fue: "personas que, como resultado de persecución, conflicto armado o violencia, han sido forzadas a abandonar sus hogares y dejar su lugar habitual de residencia, y que permanecen dentro de las fronteras de su propio país" (UNHCR, 1997, citado en Castles, 2003, p. 5). Por su parte, la Organización Internacional para las Migraciones, basado también en los Principios Rectores (Doc. ONU, E/ CN.4/1998/53/Add.2), define a las Personas Desplazadas Internamente como:

Personas o grupos de personas que se han visto forzadas u obligadas a huir o dejar sus hogares o su residencia habitual, particularmente como resultado o para evitar los efectos de un conflicto armado, situación de violencia generalizada, violación de los derechos humanos o desastres naturales o humanos y que no han atravesado una frontera de un Estado internacionalmente reconocido. ${ }^{1}$

Existen, por diferentes causas, Personas Desplazadas Internamente y Personas Desplazadas Externamente. A estas últimas comúnmente se les llama "refugiados", pero es una categoría legal bastante restringida, ya que la

${ }^{1}$ Véase https://publications.iom.int/system/files/pdf/iml_34_glossary.pdf 
mayoría de estas personas huyen por razones que no son reconocidas por el régimen internacional de refugiados (Castles, 2003).

Migración forzada es el movimiento o desplazamiento de personas, familias, grupos, y hasta de localidades, hacia otro lugar para protegerse, refugiarse y vivir. "Migración forzada" se entiende como la categoría general para incluir a todos los desplazamientos forzados y algunos tipos de migración socioeconómica que también pueden ser forzados.

Por otra parte, Márquez y Delgado (2011), así como Castles (2003), han hecho por separado tipologías de migración forzada y colocan a estas migraciones de finales del siglo xx y principios del xxI, en el contexto de las actuales transformaciones sociales en el mundo. Entonces, existe migración forzada por conflictos sociopolíticos y culturales; existen los desplazados del desarrollo; los desplazados por cambios ambientales y por desastres; por tráfico y contrabando de personas, y por la criminalidad y narcotráfico. Estos dos últimos tipos expresan grados extremos de degradación social, Estado fallido o debilitado, puesto que en diversos ámbitos territoriales los grupos armados del crimen organizado pretenden imponer su dominación. Además, hay algunas migraciones socioeconómicas que pueden ser forzadas; por ejemplo la migración por despojo de medios de producción y subsistencia; por exclusión social, desempleo estructural y pobreza, y por la sobrecalificación laboral relativa, -cuando las personas no encuentran en su lugar de residencia empleos acordes con su preparación, nivel y aspiración-. Estos tipos de migraciones se refieren a los desajustes en los modos de vida y trabajo derivados de la penetración, por ejemplo, de las grandes corporaciones multinacionales y la imposición de políticas neoliberales (Márquez y Delgado, 2011).

Todas estas migraciones tienen diferentes causas, pero coinciden en que son forzadas y en que, en el inicio no hay deseo personal de emigrar. También, debo decir que esta tipología es operativa y no procesual, y que las migraciones comúnmente son multicausales y en el proceso migratorio se suman otros problemas o factores que complejizan más su diagnóstico, estudio y resolución.

La migración forzada por violencia a la que hago referencia en este artículo es la ocasionada por la criminalidad y el narcotráfico que, de acuerdo con Márquez y Delgado (2011), ocurre cuando:

Las bandas del crimen organizado, que irrumpen en lugares donde el Estado propicia vacíos de poder, agreden a la población civil mediante acciones como 
asalto, extorsión, secuestro, trata de personas, violación, tortura y asesinato. La violencia desatada confronta a las fuerzas policiacas y militares contra las bandas criminales y grupos paramilitares, y termina por enturbiar la convivencialidad y desmadejar el tejido social, amén de que despoja a las familias de su patrimonio, desarticula las familias, genera paranoia y psicosis y deteriora la presencia de las instituciones. Ante el escenario de descomposición social, la población se ve obligada a emigrar para salvar la vida o mantener una cierta tranquilidad personal y familiar (p. 23).

Y para comprender el tema de las consecuencias (o de la continuidad) de la emigración forzada por violencia en familias que están viviendo en la ciudad de Mazatlán, retomo el concepto de integración como el proceso por el cual las personas pasan a formar parte de un todo (una localidad, una ciudad o una sociedad), pero reconociendo las diferencias y los afanes de los grupos. También retomo los tres tipos de migrantes aculturados que construyó Mayer (1963, pp. 10-11) para comprender la idea y el significado de los problemas de la aculturación en una sociedad moderna: el migrante que tiene una "cultura doble" y que puede ir y venir en los ambientes rurales y urbanos manteniendo el conjunto de pautas heredadas en estado latente; el migrante "rústico", que sigue comportándose como tal, pero extraño en la ciudad, y el migrante "renegado", que acepta forzosamente las nuevas pautas culturales, pero es un inconforme en sentido cultural.

¿Por qué familia? En este trabajo se considera a la familia como una categoría mediadora para explicar la migración. Es decir, nos permite conocer cómo la experiencia migratoria forzada por la violencia y las condiciones estructurales generan cambios en las familias en el curso de vida de los individuos.

\section{METODOLOGÍA}

Para el proceso de investigación opté por el método cualitativo a través -además de la observación- de la entrevista a profundidad. Este tipo de entrevista permite el aprendizaje sobre lo que es importante en la mente de los informantes: sus significados, perspectivas y definiciones, el modo en que ellos ven, clasifican y experimentan el mundo. Sin embargo, trabajé con entrevistas a profundidad semiestructuradas con una guía para no perder el eje 
analítico y los subtemas que se interesaba conocer; por ejemplo: la experiencia migratoria, la integración de los miembros de las familias y la vida en la ciudad de Mazatlán.

Las entrevistas se realizaron a miembros ${ }^{2}$ de cuatro familias entre 2014 y 2018, principalmente a los padres e hijos jóvenes y adultos. Se analizó su discurso como perspectiva para dar sentido con base en su contexto construido. Cabe mencionar que tres familias viven en el asentamiento irregular San Antonio y otra en la colonia Francisco Villa de Mazatlán.

\section{MIGRACIÓN FORZADA POR LA VIOLENCIA EN MÉXICO}

En nuestro país, la migración forzada o el desplazamiento forzado se empezó a documentar a partir de la insurrección zapatista en la década de 1990 en Chiapas. Desde entonces, se han hecho públicos desplazamientos forzados por distintas causas como las étnicas, religiosas, políticas, delictivas, agrarias, "extractivistas", por construcción de infraestructura, por "causas naturales" o desastres humanos. Pero, de acuerdo con el Internal Displacement Monitoring Centre y Norwegian Refugee Council (2011), posiblemente la migración de mayor impacto ha sido la causada, desde 2006, por la violencia de alta intensidad relacionada con los cárteles de la droga y por las respuestas policiaca y militar del gobierno mexicano, que constituye un conflicto armado interno conocido como la "guerra contra el narcotráfico".

Según Reynolds (2014), el país pasa por una crisis humanitaria encubierta, ya que comunidades rurales enteras han sido expulsadas por los cárteles de la droga, los cuales tratan de apoderarse de sus tierras y recursos naturales. Así, familias se han visto forzadas a huir dejando sus hogares y medios de subsistencia como consecuencia de los asesinatos selectivos, secuestros y extorsiones.

De este modo, los grupos armados no estatales usan la violencia para su beneficio, el control territorial de las rutas de tráfico y para neutralizar a las organizaciones con las que compiten, a menudo en colaboración con el propio Estado. Los traficantes de drogas y otros grupos criminales en México

${ }^{2}$ Para garantizar el anonimato y la seguridad de los integrantes de las familias entrevistadas, se le asignó a cada uno un nombre diferente. 
fueron responsables de miles de muertes de civiles y secuestros que aterrorizaron a las poblaciones locales; además de que las extorsiones, las amenazas, la corrupción y la intimidación de funcionarios del gobierno condujeron al desplazamiento forzado (Bilak et al., 2015).

De acuerdo con Albuja et al. (2014), el IDMC y el NRC estimaron que, hasta 2013, había en nuestro país entre 160 y 180000 desplazados por la violencia criminal. Según Bilak et al. (2015), los mismos IDMC y el NRC estimaron que, hasta 2014, había en México al menos 281400 desplazados internos, principalmente por la violencia criminal y por la lucha del gobierno para combatir a los cárteles y a otros grupos del crimen organizado. Hasta ese año, los datos provenían de la sociedad civil y de fuentes académicas, pero no había cifras oficiales. De acuerdo con Bilak et al. (2019), el IDMC y el NRC publicaron que, hasta 2016, había 311000 desplazados internos en México por conflictos y violencia; su principal fuente fue la Comisión Nacional de los Derechos Humanos. Pero, según Desai, Ginnetti, Sémnani y Anzellini (2018), el IDMC y el NRC aseguraron que hasta 2017 se acumularon más de 345000 mexicanos en situación de desplazamiento forzado por violencia y conflictos. Tan sólo en 2017 hubo más de 20000 desplazados internos por nuevos conflictos. Y en 2018, de acuerdo con Pérez, Bachi, Barbosa y Castillo (2019), la Comisión Mexicana de Defensa y Promoción de los Derechos Humanos registró 11491 desplazados nuevos y 25 episodios de desplazamientos internos forzados masivos, principalmente por la violencia en el país. Cabe decir que, hasta diciembre de 2018, había en el mundo 41300000 personas que huyeron de la violencia y de los conflictos en 55 países y territorios (Bilak et al., 2019).

El IDMC y el NRC advierten que, dado que el gobierno de México no reconoce oficialmente el desplazamiento interno, las estimaciones de este fenómeno han sido históricamente difíciles de producir y pueden variar significativamente de una fuente a otra. Entre las razones de que haya poca información sobre los desplazamientos forzados por violencia en México y de que esta sea no sistemática, está que los eventos de este tipo son localizados en las entidades y que el fenómeno no ha sido visibilizado ni reconocido oficialmente por el gobierno mexicano. Lo que hay son estimaciones, y son realmente subregistros, porque se hacen mucho después de las acciones violentas que ocasionan los desplazamientos (Bilak et al,, 2017).

De acuerdo con el IDMc y el NRC (2011), López (2012), Salazar y Castro (2014), Albuja et al. (2014) y Mestries (2014), las entidades federativas afectadas por desplazamiento interno forzado por violencia son: Baja California, 
Sonora, Sinaloa, Chihuahua, Coahuila, Nuevo León, Tamaulipas, Durango, Zacatecas, San Luis Potosí, Veracruz, Morelos, Nayarit, Jalisco, Michoacán, Guerrero, Estado de México y la Ciudad de México. En los demás estados donde también operan los cárteles, los desplazamientos forzados no han sido muy visibles, porque se trata de desplazamientos de individuos o familias dispersas, lo que dificulta su registro.

Respecto a los patrones de los desplazamientos forzados por la violencia en México, estos son realmente cambiantes y diversos. Algunas personas y familias han sido desplazadas de su localidad en masa y dispersas, ya sea de una zona rural y semirrural a una suburbana, de una zona suburbana a una urbana, de una zona urbana a una suburbana, de una zona urbana a otra urbana, y desplazamientos intraurbanos (IDMC y NRC, 2011; Salazar y Castro, 2014; Albuja et al., 2014; Mestries, 2014).

\section{MIGRACIÓN FORZADA POR LA VIOLENCIA EN SINALOA}

Los desplazamientos forzados en el estado de Sinaloa no sólo se han presentado en la actualidad; por ejemplo, en su historia, los desastres de huracanes y las inundaciones de ríos, lagunas y esteros provocaron, en algunos casos, que la población dejara sus pueblos, temporal o permanentemente; asimismo, los desplazados (aún) por la construcción de carreteras, presas, sistemas hídricos, campos agrícolas y fraccionamientos urbanos. De acuerdo con Cañedo (2012), una situación fue la construcción de la presa Picachos en los límites serranos de los municipios de Mazatlán y Concordia que desplazó a varios pueblos, entre ellos a San Marcos, que ahora está reubicado en el Nuevo San Marcos.

Posiblemente, los desplazamientos forzados más importantes y trágicos en el estado de Sinaloa han sido los provocados por la violencia relacionada con el crimen organizado y su combate. Un antecedente muy visible se remite a mediados de la década de los setenta, con la llamada "Operación Cóndor", que consistió en la intervención del ejército en la entidad para combatir los cultivos de enervantes y al narcotráfico, acción que generó, entre otros hechos, asesinatos, desaparecidos, el recrudecimiento de la violencia y la huida de la población, sobre todo en la sierra y en los lugares donde intervinieron las fuerzas del Estado. Según Lizárraga (2002; 2004), en las siguientes dos décadas, en los años ochenta y noventa, se consolidó el desplazamiento 
forzado por la violencia. Por lo menos desde la "Operación Cóndor", el estado de Sinaloa ha experimentado violencia e inseguridad ligada al narcotráfico y a su combate, de manera recurrente con etapas muy cruentas.

Cabe decir que en Sinaloa pudiera existir otra causa de desplazamiento forzado distinta de las antes señaladas, e inclusive que interactúa, y es por acumulación de capital por desposesión (Harvey, 2005) o por despojos de tierras. La hipótesis la plantea Lizárraga (2016), y dice que atrás de la violencia de los grupos criminales, así como de las fuerzas del Estado, está el propósito por despojar de los recursos naturales a los campesinos en un marco privatizador promovido por el neoliberalismo; es decir, allanar los espacios a los grandes capitales como pueden ser los mineros, los hídricos o los energéticos -tanto nacionales como extranjeros- $y$ a otros agentes que quieran incursionar en esas actividades. ${ }^{3}$ Sin embargo, este planteamiento está más allá de los objetivos de este artículo, pero que puedo retomarlo después.

En 2006, el gobierno federal emprendió la llamada "guerra contra el narcotráfico" dando origen a una de las etapas más violentas que ha vivido el país. En Sinaloa, la violencia se hizo más extrema, con costos sociales evidentes que alcanzaron a todos los sectores sociales. Uno de los costos o consecuencias ha sido la migración forzada, principalmente en la Sierra Madre Occidental y en algunas zonas rurales del estado, aunque se sabe menos del desplazamiento forzado interurbano e intraurbano. Estos hechos de migración en Sinaloa ocurren en el contexto de violencia extrema como consecuencia de enfrentamientos entre grupos rivales del narcotráfico o del crimen organizado por territorios, plazas, mercados, cultivos, tránsito, distribución de estupefacientes y otras actividades ilícitas. Las personas y familias que emigraron lo hicieron porque sufrieron amenazas, extorsiones o alguien de la familia fue desaparecido o ejecutado por grupos criminales. Hay familias que, si bien no fueron agredidas, huyeron de sus comunidades para evadir cooptación, complicidades y/o amenazas que pondrían en peligro la vida de cualquiera de sus miembros (López, 2017).

De acuerdo con solicitudes de información propias (con folios 00234413, 00235014 y 01205618), vía Plataforma Nacional de Transparencia a la Secretaría de Desarrollo Social de Sinaloa, en marzo de 2012 había 690 familias desplazadas en once municipios de la entidad, según su padrón. En agosto del mismo año la cifra se incrementó a 1187. Y en octubre descendió a

\footnotetext{
3 Véase la aportación que se hace en este sentido en Cañedo, Vizcarra y Arias (2019).
} 
890 familias. Para junio de 2013 se tenían 1173 familias reportadas. Al siguiente año, en junio de 2014, la cifra llegó a 1189 familias desplazadas. En 2015 disminuyó a 1177 familias. Y en 2016 también bajó a 590 familias. En enero de 2018 había 1958 personas desplazadas (653 familias, aproximadamente). Y en septiembre de ese año solo hubo 496 familias en esta situación. Un año después, en septiembre de 2019, el secretario de Desarrollo Social de Sinaloa informó que en la entidad había 1750 familias desplazadas y 572 en la zona sur, y de estas la gran mayoría refugiada en Mazatlán (Arredondo, 2019).

Cabe decir que la Secretaría ha hecho depuraciones en su registro de las familias que, supuestamente, han regresado a sus comunidades, pero cuestiono ese registro, porque no todas las familias informan a las autoridades sobre su decisión de retornar o no hacerlo. De hecho, hay familias que no acuden a las autoridades ni siquiera por ayuda y no son registradas en el padrón. Si bien las autoridades estatales hacen un esfuerzo por detectar los municipios afectados y registrar el número de familias o personas desplazadas, prevalece la dificultad de hacer un censo, porque no todos los desplazados acuden a las autoridades para denunciar su situación. Además, no todos los desplazamientos son masivos, sino que en muchos casos han sido dispersos, lo que dificulta que sean visibles y contabilizados.

De acuerdo con las solicitudes de información (con folios 00234413, 00235014 y 01205618) y con una revisión realizada del periodo 2006-2018 en los periódicos de cobertura local como Noroeste, Riodoce, El Debate y El Sol de Mazatlán, así como en medios informativos de cobertura más amplia como Proceso, El Universal, Animal Político y Sinembargo.mx, podemos darnos cuenta que, por lo menos, trece de 18 municipios de Sinaloa presentaron migración forzada por violencia y que muchas de las familias se desplazaron desde sus comunidades a la cabecera de su municipio y a las principales ciudades del estado. Por ejemplo, a las cabeceras de El Fuerte, Choix, Sinaloa de Leyva, Guamúchil, Mocorito, Cosalá, Culiacán, San Ignacio, Elota, Mazatlán, Concordia, Rosario y en Surutato, Badiraguato. Y en algunas cabeceras se formaron asentamientos de estas familias; por ejemplo en Guamúchil, Choix, Culiacán, Mazatlán, Concordia y en la localidad de Surutato.

En la ciudad de Mazatlán y en la Sindicatura de Villa Unión se formaron algunos asentamientos en zonas irregulares de familias desplazadas por la violencia y la inseguridad que provienen de pueblos del mismo municipio y de algunos municipios aledaños como son Concordia, San Ignacio y Rosa- 
rio. Cabe mencionar que también hay familias con esta situación viviendo de manera dispersa en colonias de Mazatlán y de su periferia.

\section{CUATRO EXPERIENCIAS FAMILIARES DE EMIGRACIÓN FORZADA POR LA VIOLENCIA EN LA SIERRA DE MAZATLÁN Y CONCORDIA}

De acuerdo con el testimonio de las cuatro familias entrevistadas, tuvieron una experiencia migratoria intempestiva que no desearon $y$, por lo tanto, no tuvieron un amplio margen de planeación. Fue intempestiva, porque la violencia y la inseguridad perpetrada por grupos del crimen organizado los obligó a abandonar sus comunidades de improviso para ponerse a salvo en la ciudad de Mazatlán. Y fue (o es) trágica porque dos de las familias sufrieron la muerte o la desaparición de algunos de sus miembros o parientes, mientras que las otras fueron amenazadas para que dejaran sus comunidades, y porque la violencia física casi se concreta con acciones de muerte. Pero, además, nuevos problemas y dificultades tuvieron (o tienen) que sufrir y enfrentar con la migración forzada.

Por ejemplo, la familia de Manuel y Teresa emigró en mayo de 2013, desde la comunidad de El Tecomate, Sindicatura de La Noria, a la cabecera municipal de Mazatlán, para protegerse de la presencia de dos grupos criminales que buscaban el dominio de su territorio, ya que las autoridades poco hacían para darles seguridad. Para Manuel, el peligro consistía en que, si se enfrentaban a balazos los grupos criminales, las familias podrían salir heridas por estar en medio del tiroteo. Según Manuel, a su familia no la molestaban porque tenía buena relación con ambos grupos, pero a pesar de ello, les tenían miedo, porque eran delincuentes y a su familia le tocó ver cuando exponían cadáveres en las calles de la comunidad provocando el terror. Su hijo Juan no quería dejar la comunidad, pero, finalmente, lo hizo por miedo y porque los delincuentes lo acosaban y le quitaban el dinero, y revela que la población fue amenazada para que abandonara la comunidad. Teresa, la mamá de la familia comenta que su hija Rosa se resistía a dejar El Tecomate porque allá estaba con su esposo e hijas. Pero la violencia alcanzó al esposo de Rosa y a otros parientes de él en noviembre de 2014; los "levantaron", y ella mantuvo por un tiempo la esperanza de encontrarlo. Sin embargo, tuvo que emigrar con sus 
hijas a Mazatlán con sus papás; estos antes ya habían emigrado, en abril de 2015, porque habían sufrido amenazas.

La experiencia de emigrar para la familia de Manuel y Teresa fue intempestiva por el miedo que ocasionaron las ejecuciones de los pobladores de la comunidad y por las amenazas. La decisión de irse la tomaron los padres cuando otras familias ya lo hacían en medio de la zozobra y la desconfianza hacia el ejército que supuestamente los cuidaba. La familia pensó que podía regresar una vez que se tranquilizara la situación, pero eso no sucedió.

Se observa que la familia de Manuel y Teresa experimenta una emigración forzada por el miedo a la situación de violencia y de inseguridad de su pueblo; no es una migración voluntaria ni una con amplio margen de planeación en la mayoría de sus miembros. Los integrantes de la familia coinciden en la causa de emigración (la violencia perpetrada por los grupos criminales), pero los motivos o razones detallan esas causas según la situación de ellos.

Por otro lado, en la familia Carlos y Esperanza se pueden ver migraciones forzadas de manera intempestiva y cruenta por la violencia sufrida y perpetrada por criminales. La familia de Carlos y Esperanza dice que dos veces ha emigrado desde la Sindicatura de La Noria a la ciudad de Mazatlán por tres eventos violentos perpetrados por grupos criminales que afectaron directamente a los miembros de la familia.

Cuentan que, a partir de 2010, la familia vive tres acontecimientos violentos. En el primero les balacearon la casa, pero los papás se resistieron a abandonar la comunidad porque, aparentemente, se trató de una confusión; permanecen allí por cuatro meses. Fue hasta el segundo hecho violento, cuando balacearon la casa del hermano de Esperanza, que los papás tomaron la decisión de abandonar la Sindicatura y dirigirse a Mazatlán. En la cabecera de Mazatlán permanecieron dos años y luego decidieron retornar a La Noria, porque aparentemente se había tranquilizado la situación de inseguridad. La familia se quedó en la comunidad algunos meses, pero sucede el tercer hecho violento, que fue cuando "levantaron" a un hijo y a un hermano de Esperanza, y volvieron a emigrar hacia la ciudad de Mazatlán.

Los papás -Carlos y Esperanza- dicen que decidieron irse de la comunidad y llevarse a su familia en las dos ocasiones que han emigrado porque era difícil la situación en la que se encontraban. El motivo principal de abandonar La Noria fue para evitar que el grupo criminal obligara a sus hijos varones a que se integraran a sus filas; es por eso que los agredieron a balazos. De 
hecho, los hijos no podían realizar sus actividades agropecuarias en el monte porque se convirtió en un área peligrosa donde campeaban los criminales.

Otro caso de migración forzada es el de la familia de Rubén y Cecilia, que decidió emigrar a la ciudad de Mazatlán porque el 24 de diciembre de 2012 un grupo de criminales arribó a su pueblo El Platanar de Los Ontiveros, municipio de Concordia, y ejecutó a nueve personas, aparentemente sin estar ligados o estar en contra de ellos. Según Rubén, decidieron emigrar cuando, en una noche que debería ser de felicidad, ocurrió una tragedia que marcó la vida de los pobladores. El miedo y la zozobra fue lo que siguió. Todas las familias de la comunidad entendieron que, si los criminales regresaban seguirían ejecutando a más personas, por lo que abandonaron la comunidad, en las primeras horas de Navidad de 2012, quedando un pueblo "fantasma".

El siguiente caso es la experiencia de una familia que dos veces ha sido desplazada por diferentes causas, como vemos a continuación. La causa del primer desplazamiento de la familia de Leonor y Fabiola -de San Marcos al Nuevo San Marcos del municipio de Mazatlán-fue porque la localidad quedó adentro de las tierras anegadas por la presa Picachos y una tormenta precipitó la inundación del pueblo que puso en peligro a los habitantes. El segundo desplazamiento - de Nuevo San Marcos a la colonia Francisco Villa de la ciudad de Mazatlán- fue por la situación de violencia que había en esa región.

Leonor y Fabiola temían ser dañadas por la violencia que acosaba fuertemente a su pueblo y por lo desprotegidas que se sentían, ya que no tenían más familia en el Nuevo San Marcos. Ellas emigraron intempestivamente cuando una parte del pueblo fue amenazado y porque varios hechos de violencia casi les tocaba. También manifiestan que emigraron forzadamente a Mazatlán porque la hija mayor ya se encontraba en esa ciudad estudiando una carrera profesional. En esta situación se combinaron el miedo a ser dañadas por la violencia y la inseguridad con otros motivos como la falta de apoyo familiar, la situación de vulnerabilidad y la reubicación familiar.

En general, las cuatro familias que dan su testimonio manifestaron que tuvieron una experiencia migratoria forzada intempestiva $y$, por lo tanto, no tuvieron amplio margen de planeación. Por lo menos, al inicio no tuvieron deseo personal de emigrar.

La migración forzada por la violencia y la inseguridad es grave, porque violenta la forma de vida de las personas, pero cuando va acompañada de hechos violentos que sufren directamente los miembros de las familias, se convierte en una tragedia. 


\section{UNA ZONA DE EMIGRACIÓN FORZADA POR LA VIOLENCIA EN EL SUR SINALOA}

Los pueblos de donde provienen estas cuatro familias no son los únicos de la región donde ha habido migración forzada por violencia, también se ha presentado en otros pueblos cercanos de la sierra de Mazatlán y Concordia, que tuvieron la misma situación a partir del año 2006, cuando empezó la lucha por el control del territorio por parte de grupos del crimen organizado.

Por ejemplo, El Tecomate de La Noria, junto con otras comunidades, conforman una zona de alta migración forzada por violencia. De acuerdo con Manuel, Teresa y Juan, hay por lo menos trece comunidades que están casi o totalmente abandonadas debido a la violencia y la inseguridad en la zona serrana entre los municipios de Mazatlán y Concordia; esos pueblos son: El Tecomate, El Platanar de Los Ontiveros, Zaragoza, Aguacaliente, El Tiro, Los Laureles, El Zapote, Los Arrayanes, Guamúchil, La Chapalota, El Pueblo, La Osa y Los Naranjos. Estos pueblos son conocidos por la prensa local como "zona de miedo", porque ahí campean grupos del crimen organizado que luchan por el control del territorio, de los cultivos de enervantes y de la distribución de drogas, lo que ha ocasionado una cruenta guerra, así como una violencia dirigida -directa o indirectamente- a la población civil, de la cual una parte ha emigrado a las cabeceras de Mazatlán y Concordia, principalmente.

Por su parte, Carlos y Esperanza también aseguran que hay muchas familias que emigraron por la violencia desde La Noria y de otros pueblos cercanos en el municipio de Mazatlán. Ellos dicen que hay otros pueblos como San Marcos y Juantillos que también están casi o totalmente abandonados debido a la violencia perpetrada por grupos del crimen organizado. Esta familia reconoce que La Noria está dañada, pero coincide con la familia de Manuel y Teresa en que es aún más violenta la "zona de miedo" cercana a La Noria, en donde las comunidades también están casi deshabitadas.

Rubén también coincide con las familias anteriores en que los pueblos cercanos a El Platanar de Los Ontiveros, municipio de Concordia, están casi abandonados por el fenómeno que nos ocupa. Son los casos de Zaragoza, El Llano, El Tiro, El Zapote y Guamúchil, entre otros. Desafortunadamente, esto nos dice que, por lo menos en esa región, el crimen organizado ha ganado territorio al Estado, ya que este se encuentra debilitado, posiblemente por la corrupción y la impunidad. 


\section{EL DESPLAZAMIENTO Y ESTRATEGIAS DE SUPERVIVENCIA DE LAS FAMILIAS}

En este apartado, de acuerdo con las experiencias de las cuatro familias desplazadas por la violencia, se presenta la ayuda familiar y la utilización de recursos disponibles como estrategias de supervivencia de los desplazados, desde su salida de su lugar de origen hasta su llegada y asentamiento inicial en la ciudad de Mazatlán. El apoyo familiar se volvió muy importante -más que otra ayuda- porque permitió que las familias lograran desplazarse con relativa certidumbre hacia el refugio proporcionado por los familiares en Mazatlán. El apoyo de la familia viene a cubrir casi por completo la ausencia de ayuda de las autoridades, ya que ellas no les brindaron a las familias seguridad, protección, resguardo o asilo.

Por ejemplo, en el caso de la familia de Manuel y Teresa, para iniciar el traslado, utilizó el apoyo de otros hijos que ya vivían en Mazatlán para trasladarse al asentamiento donde ya los esperaban. Por lo intempestivo del desplazamiento, la ayuda de otros integrantes de la familia y los recursos que se tenían se volvieron muy importantes o fue lo primero que se tomó en cuenta como estrategia de supervivencia para trasladarse a Mazatlán.

El siguiente caso de la familia de Carlos y Esperanza es similar al anterior, donde la ayuda familiar, los recursos propios y el capital social son lo más importante. En las dos migraciones forzadas por violencia que ha realizado esta familia, para el traslado a Mazatlán ha contado con recursos para rentar una camioneta y llevarse consigo las pertenencias que tenían en la comunidad, lo que significó un ahorro, ya que no tuvieron que gastar más dinero en cosas y utensilios básicos. Sin embargo, el apoyo de la hija de Carlos y Esperanza fue muy importante en el primer desplazamiento, porque ayudó a su familia con un refugio en su casa de Mazatlán. Pero la hija ya no pudo sostener la ayuda por diferencias con su marido sobre el apoyo ofrecido. Ya con sus propios recursos y después de rentar una casa por unos meses, Carlos decide buscar un terreno en la invasión San Antonio donde se instala con su familia. En el segundo desplazamiento, la familia contó con el apoyo del líder del asentamiento irregular para obtener otro terreno y construir una casa de madera y lamina. Aquí, se puede ver que la estrategia resultante para llevar acabo los desplazamientos fue la utilización de la ayuda de la hija, los recursos propios y el capital social generado durante la última migración. 
Por su parte, la familia de Rubén y Cecilia aceptó la ayuda familiar para desplazarse, así como la ayuda del ejército para regresar a la comunidad y recuperar sus pertenencias. La familia de Rubén y Cecilia, junto a otras familias, abandonaron en grupos la comunidad de El Platanar de Los Ontiveros de manera inesperada al siguiente día que ocurrió el multihomicidio de personas. Algunas familias se dirigieron a la cabecera municipal de Concordia y otras a Mazatlán por su propia cuenta. A los siguientes días, algunas personas como Rubén pudieron regresar por sus pertenencias, pero escoltados y cuidados por soldados del ejército. Así, el acompañamiento que hicieron los soldados a las familias de la comunidad para recuperar las pertenencias resultó de muy poca ayuda, porque el ejército no dio garantías de restablecer la seguridad y la confianza de los pobladores para retornar.

La familia de Rubén y Cecilia contó con el apoyo de los hermanos de Rubén, primero, para trasladarse a Concordia y, después, para establecerse en Mazatlán. Los hermanos y otros parientes de Rubén prefirieron quedarse en Concordia. La familia vivió un mes en casa de la hermana de Rubén, que rentaban. Luego, Rubén consiguió trabajo y continuó rentando casa por ocho meses. Estando en Mazatlán, Rubén se enteró por su tío que podían obtener un terreno en la invasión San Antonio, donde permanecen ahora, cerca de donde también viven sus papás para ahorrarse el gasto de la renta y con la esperanza de tener una propiedad. De nueva cuenta, se observa que se emigra con los recursos y el apoyo familiar que se tiene o con el de personas de suma confianza que son muy importantes para la sobrevivencia de la familia ante la inseguridad y la incertidumbre. En este tipo de migración lo primero es salvar la vida, después se planea y se valora una nueva vida.

El caso de la familia de Leonor y Fabiola es un poco diferente porque sobresalieron sus propios recursos para emigrar desde Nuevo San Marcos a una colonia de la ciudad de Mazatlán. Ellas aseguran que no tienen mucha familia de apoyo, pero con la venta de sus tierras de San Marcos para que el gobierno construyera la presa Picachos compraron la casa de Mazatlán. Leonor se resistía a irse Nuevo San Marcos a Mazatlán, pero una vez que su hija mayor se fue al puerto a estudiar una carrera profesional y que se agudizó la violencia y la inseguridad en la comunidad, decidieron dejar el pueblo.

Como se observa, más que la ayuda familiar sobresalieron los recursos propios para pagar la segunda emigración forzada a Mazatlán con relativa planeación. A pesar de la resistencia de Leonor por dejar el pueblo, a decir de ella, le importó más la familia para que no sufriera la inseguridad, por lo 
que hizo un gasto considerable de su dinero para irse a vivir a Mazatlán. La ayuda familiar importa, pero cuando no se tiene o es insuficiente se recurre a la ayuda externa, pero, en este caso, fueron afortunadas de tener la capacidad económica propia.

\section{LA INTEGRACIÓN DE FAMILIAS DESPLAZADAS POR LA VIOLENCIA EN LA CIUDAD DE MAZATLÁN}

En las familias entrevistadas el proceso de integración en la sociedad receptora es la continuidad de la emigración forzada, puesto que se huye de la violencia y la inseguridad a otro lugar para refugiarse y vivir. La migración forzada por violencia y la integración son vistas, no como etapas separadas, sino parte de un proceso continuo de la migración y de las experiencias de las familias. Del análisis de la integración de algunos miembros de estas familias que se asentaron en la ciudad de Mazatlán, observo que han experimentado diferentes maneras de aculturación y distintos grados de integración a diferentes sectores de la sociedad, a ámbitos y espacios de la ciudad, y en ello desempeñan un papel importante la edad, el género, la educación, el trabajo, la economía, la nostalgia, el (des)arraigo, la cultura y la misma experiencia migratoria.

Antes de continuar con el análisis de la integración, hago una descripción de la identidad étnica de las familias desplazadas por la violencia que viven en la ciudad de Mazatlán. Las familias provienen de comunidades o pueblos pequeños de la sierra compartida entre los municipios de Mazatlán y Concordia. En ellos es característico el apego a la libertad de la naturaleza $y$ al terruño. En la familia se implementan los usos y costumbres tradicionales donde el padre es la máxima autoridad, el responsable y proveedor de la familia, mientras que en el hogar la madre es la encargada de la crianza de los hijos, y su participación más allá de este entorno es limitada; el padre participa más en otros ámbitos del pueblo. Y los hijos tienden a reproducir esos patrones, con algunas modificaciones que les proporcionan la televisión y otros aparatos de comunicación. Lo social y las actividades económicas se realizan entre el pueblo y el monte. El trabajo (no asalariado) del campo que requiere destreza y fortaleza lo realizan los hombres, mientras que las mujeres realizan principalmente la labor doméstica y algunas actividades agropecuarias. La producción de alimentos es de autoconsumo, pero tienen la opción de comprar alimentos en pequeñas tiendas. 
Por su parte, para Manuel y Teresa (de 64 y 55 años, respectivamente), padres de familia que provienen del pueblo El Tecomate del municipio de Mazatlán, el proceso de integración y la vida en la ciudad de Mazatlán se les ha dificultado, porque en el hogar los usos y costumbres son diferentes, en el empleo y en la economía los requerimientos son otros, y porque la etapa de vida en la que se encuentran hace más difícil la integración. De acuerdo con Mayer (1963), ellos responden más al tipo de migrante "rústico"; es decir, que siguen comportándose como tales y extraños en la ciudad. El caso de su hijo Juan (de 36 años) se parece más al migrante "renegado" que acepta forzosamente las nuevas pautas y normas culturales, pero también es un inconforme de la dinámica económica y laboral que presenta la ciudad, porque el salario no alcanza para proveer y para trabajar, además de fortaleza física se necesitan otras cualidades educativas, psicológicas y sociales. El caso de su hija Rosa (madre de 25 años de edad) se parece al de sus papás, ya que gracias al ambiente ruralizado del asentamiento irregular donde viven y a la convivencia con otras familias de su pueblo de origen, le permite seguir conservando sus usos y costumbres de la mujer madre, por lo que su integración coincide con el tipo de migrante "rústico", resultando diferente en la ciudad, donde la participación de la mujer ha ido creciendo en varios sectores y espacios.

Para Carlos y Esperanza (de 60 y 42 años, respectivamente), padres de otra familia, la vida en La Noria era mejor antes de desatarse la violencia, porque allá no tenían problemas con los servicios públicos básicos, como sí los tienen en la invasión San Antonio donde viven en Mazatlán; además, en su pueblo tenían una producción agropecuaria de autoconsumo y Carlos hacía carbón de madera de donde obtenía ingresos para solventar los gastos de la familia. Para ellos, la vida en La Noria era menos costosa y la familia tenía más recursos para satisfacer las principales necesidades. De acuerdo con Mayer (1963), el caso de la integración de Carlos y Esperanza es difícil de clasificarlo en un solo tipo de migrante aculturado, ya que tiene una combinación de características. Ellos han emigrado por la violencia dos veces de la Sindicatura de La Noria a la ciudad de Mazatlán, han ido y regresado, conociendo y aprendiendo del medio rural y urbano (migrantes con "cultura doble"). Pero es en el hogar y la familia, en el asentamiento irregular, donde manifiestan más las pautas de usos y costumbres tradicionales (migrantes "rústicos"). El caso de la integración de Inés (de 29 años), la nuera, se parece al migrante que tiene una "cultura doble", porque también ha vivido y ha aprendido en 
ambientes rurales y urbanos en varios momentos, pero mantiene el conjunto de pautas rurales heredadas en estado latente.

Otra familia es la de Rubén (de 40 años). El caso de la integración de este padre de familia se da principalmente en los sectores social y económico, porque su empleo -en el que lleva más de dos años en una empresa de productos de limpieza- le ha ayudado a socializar en la invasión San Antonio y en otras zonas de la ciudad, $y$ ha apoyado a la familia con relativa estabilidad económica. Él acepta su vida en la ciudad, pero dice que era mejor en El Platanar de Los Ontiveros, municipio de Concordia, ya que el cambio fue social, económico, cultural y hasta ambiental. El caso de la integración de Rubén es diferente a los demás, porque aceptó forzosamente las nuevas normas laborales (empleo asalariado, horario) y de la ciudad, pero ya no está inconforme, incluso parece estar viendo su futuro en Mazatlán, porque hay más educación y oportunidades para sus hijos. Sonia (de 17 años), la hija mayor, se integró más rápido al asentamiento, a la escuela, al trabajo, en general a la ciudad, por su juventud y apertura al cambio, ya que tiene otro punto de vista de su pueblo de origen, de la vida, y porque no vivió tantos años en su pueblo como sus papás y abuelos. Sonia parece tener una "cultura doble", pero con menos arraigo al conjunto de pautas heredadas. Caso contrario es el de Matilde (de 68 años), la abuela paterna, quien ha tenido más dificultad para integrarse a la invasión y a la ciudad, por la edad y porque vivió la mayor parte de su vida en El Platanar de Los Ontiveros y tiene más arraigado los papeles y las costumbres de su pueblo. Sin embargo, Matilde ha aceptado forzosamente algunas pautas culturales referentes a la familia, el trabajo y el estilo de vida de la invasión.

La cuarta familia es la de Fabiola (de 22 años), que proviene de Nuevo San Marcos, municipio de Mazatlán. Ella es una madre soltera que ha podido integrarse a la ciudad, pero al comienzo le fue difícil porque la ciudad es completamente diferente a su pueblo. A ella le parecía diferente la sociedad, la economía, el ambiente y hasta el clima. Pero, para Leonor (de 53 años), madre de Fabiola y soltera, le ha sido difícil integrarse y acostumbrarse a la colonia Francisco Villa, donde viven, y a otras zonas de Mazatlán. Fabiola ve un futuro mejor para ella en la ciudad, porque en esta puede trabajar y hay más fuentes de empleo para las mujeres, lo que le permite independizarse. Sin embargo, Leonor piensa que no es así para ella, porque para personas de su edad, ya sea mujer $u$ hombre, casi no hay empleos en la ciudad. El caso de la integración de Fabiola es parecido al de Sonia, hija de Rubén, porque si bien en el inicio tuvo dificultades para integrarse a la colonia y a la ciudad, se ha 
integrado más rápido que su mamá, porque es joven y ha desarrollado mayor apertura y disponibilidad al cambio. Fabiola tiene una "cultura doble", pero muestra menos arraigo a las pautas heredadas de su pueblo. Caso contrario es el de Leonor, quien tiene menor apertura y se resiste al cambio, porque ha vivido más tiempo en un ambiente rural y conserva más arraigo. Para ella todo ha sido diferente en la ciudad y ha sido difícil adaptarse, pero poco a poco ha aceptado forzosamente algunas pautas culturales referentes a la familia, el trabajo, la economía y el estilo de vida de Mazatlán.

\section{REDES SOCIALES Y FAMILIARES EN LA CIUDAD DE MAZATLÁN}

La utilización de las redes sociales y familiares en la ciudad de Mazatlán son importantes para entender la solidaridad, la convivencia y las estrategias de supervivencia de las cuatro familias desplazadas por la violencia, porque ayudaron a las familias a tener una mayor posibilidad de superar algunas necesidades, así como a mantener o mejorar sus condiciones de vida. Estas redes vienen a cubrir o a sustituir casi por completo la ayuda de las autoridades.

Por ejemplo, para Manuel y Teresa, la ayuda proporcionada por los miembros de la familia y de parientes ha sido muy importante para obtener trabajos e ingresos que, según ellos, a sus edades (64 y 55 años, respectivamente) es difícil obtener en Mazatlán. La familia ha sido apoyada también por otras personas con ayuda alimentaria, con vestido y con algunos objetos domésticos. Así, Manuel y Teresa dicen contar con el apoyo económico de los hijos, y ellos, a su vez, cuidan a los nietos más pequeños, por lo que en esta familia, padres e hijos se apoyan mutuamente. Además, Manuel cuenta con el apoyo de dos hermanos que viven en Mazatlán y de sus sobrinos, que lo apoyan con trabajo en ocasiones. Por su parte, Juan señala que se reúne muy poco con otras personas de su pueblo en Mazatlán, porque el trabajo que realiza le quita la mayor parte del tiempo, y el tiempo libre lo dedica a la familia. Además, ir a visitar a las personas conocidas implicaría un gasto que no puede solventar, por lo que Juan evita hacerlo. Y Teresa dice que su familia, y otras que viven en la invasión San Antonio, reciben apoyo regularmente, por parte de una iglesia cristiana de estadunidenses, con despensas, comida, ropa y objetos domésticos, lo que significa que las familias ahorran cuando son visitadas, al menos, dos veces al mes. 
En la siguiente familia, que es la de Carlos y Esperanza, se presenta un caso de solidaridad en diciembre de 2013, cuando es asesinado su hijo Gabriel, y tanto el líder de la invasión San Antonio como los vecinos apoyaron a la familia con casi todos los gastos del sepelio; el apoyo que fue muy significativo, porque los papás en ese momento no contaban con dinero para los gastos del sepelio y no deseaban la otra opción, que era la fosa común. El evento trágico acercó más a la familia con los vecinos y con el líder de la invasión, con los que se vio agradecida.

Por su parte, la familia de Rubén y Cecilia estuvo poco dispuesta a hablar sobre la convivencia con los vecinos de la invasión; quizá por miedo y desconfianza a los vecinos que no son parte de la familia. Otro punto que explica la poca convivencia es que la vivienda se encuentra rodeada de pocas casas habitadas, ya que están asentados en la orilla de la invasión San Antonio.

Leonor y Fabiola, por su parte, manifiestan que tienen poca convivencia con personas y familias de Nuevo San Marcos, que viven en Mazatlán, pero que tienen mayor convivencia al interior de la familia, así como con sus vecinos en la colonia donde habitan y en los espacios de trabajo. Las nuevas relaciones de la familia en la ciudad ha abierto a las hermanas la posibilidad de trabajar y estudiar.

Como podemos ver, las cuatro familias realizan estrategias de supervivencia en la ciudad a partir de sus redes sociales y familiares que, en la convivencia con parientes, amigos, paisanos y vecinos logran apoyo o solidaridad para cubrir ciertas necesidades básicas o para superar algunas de sus condiciones socioeconómicas, como obtener trabajo e ingresos.

\section{EL (NO)RETORNO}

Para los padres de las cuatro familias, el retorno definitivo parece lejano, ya que se encuentran entre el querer y no poder hacerlo, porque sus pueblos fueron trastocados y no se les ha garantizado las condiciones de seguridad y menos se les ha restablecido la forma de vida de sus comunidades. Además, en las familias persiste el miedo, la desconfianza, la vulnerabilidad y la desprotección de las autoridades, que son los principales obstáculos junto con los antes mencionados, que impiden a las familias tomar la decisión de retornar y hacerlo efectivo. 
Las cuatro familias dicen que las autoridades no les han resarcido su situación de desplazadas por la violencia en sus pueblos ni en otro lugar; lo que significa el deber de restablecerles o repararles el sistema de relaciones entre los sectores social, económico, político, cultural y religioso, si así lo exige la comunidad.

\section{CONCLUSIONES}

Posiblemente, las migraciones forzadas más importantes en el estado de Sinaloa han sido las provocadas por la violencia relacionada al crimen organizado y su combate. Un antecedente muy visible se ubica a mediados de la década de los setenta con la llamada "Operación Cóndor" para combatir el narcotráfico, que produjo el recrudecimiento de la violencia y la huida de población, sobre todo en la sierra. En las siguientes dos décadas, en los años ochenta y noventa se consolidó el desplazamiento forzado por violencia (Lizárraga, 2002; 2004). Por lo menos, desde esa operación el estado de Sinaloa ha experimentado violencia e inseguridad ligada al narcotráfico y a su combate, de manera recurrente con momentos o etapas muy cruentas.

En 2006, el gobierno federal inició la llamada "guerra contra el narcotráfico", dando origen a una de las etapas más violentas que ha experimentado el país. En Sinaloa, la violencia se hizo más extrema con costos sociales que alcanzan a todos los sectores sociales. Uno de estos costos ha sido la migración forzada, principalmente en la Sierra Madre Occidental y en algunas zonas rurales del estado.

Es en este contexto que se da la migración de personas y familias que dejaron sus pueblos por la violencia y la inseguridad en el sur de Sinaloa. Así, las familias entrevistadas al inicio del proceso no tuvieron el deseo personal de emigrar, porque fue una experiencia migratoria forzada intempestiva y sin amplio margen de planeación, y podría decirse que fue una migración involuntaria; marcada por la tragedia, la vulnerabilidad social y por el miedo.

La migración forzada por la violencia y la inseguridad es grave, porque violenta la forma de vida de las personas, pero cuando va acompañada de hechos violentos que sufren los miembros de las familias o del pueblo, se convierte en una tragedia. Así, las familias en cuestión tuvieron una experiencia migratoria trágicamente inesperada, porque la violencia y la inseguridad 
perpetrada por grupos del crimen organizado los afectó y los forzó a dejar sus comunidades para ponerse a salvo en la ciudad de Mazatlán.

La vulnerabilidad social y el miedo han aparecido desde el comienzo del proceso afectando a las personas en sus decisiones familiares y en las de la vida diaria, han estado presentes en las decisiones de emigrar, a qué lugar ir y a quién pedir ayuda. El miedo a los grupos criminales que provocó la emigración persiste en la vida de estas familias en la ciudad de Mazatlán, ya que desean retornar de manera definitiva a sus comunidades, pero no pueden hacerlo porque todavía se sienten vulnerables y las garantías de seguridad y las condiciones no están dadas o restablecidas.

Los pueblos de procedencia de las familias entrevistadas no son los únicos de la región donde se ha presentado migración forzada por violencia, también ha habido una situación similar en otros pueblos cercanos. Estos son conocidos por la prensa local como "zona de miedo", porque ahí campean grupos del crimen organizado que pelean por el control del territorio, de los cultivos y la distribución de enervantes, así como de los narcolaboratorios, lo que ha ocasionado una feroz guerra y una violencia dirigida, directa o indirectamente a la población civil, de la cual una parte ha emigrado a las cabeceras de Mazatlán y Concordia, principalmente.

Las familias en cuestión utilizaron como estrategia de supervivencia la ayuda familiar y los recursos disponibles que se tenían, desde el desplazamiento hasta la llegada y el asentamiento inicial en la ciudad de Mazatlán. En esta fase el apoyo familiar se vuelve muy importante, porque permitió que las familias lograran desplazarse con relativa certidumbre hacia el refugio proporcionado por los familiares en Mazatlán. El apoyo de la familia cubre casi por completo la ausencia de la ayuda de las autoridades, ya que ellas no les brindaron a las familias seguridad, protección, resguardo o asilo.

En las familias entrevistadas el proceso de integración a la ciudad de Mazatlán es la continuidad de su emigración forzada, puesto que huyeron de la violencia y la inseguridad a esa ciudad para refugiarse y vivir. Así, la migración forzada por violencia y la integración son vistas, no como etapas separadas, sino como parte de un proceso continuo de la migración y de las mismas experiencias de las familias. En la integración de algunos miembros de estas familias, observo que ellos han experimentado diferentes maneras de aculturación y distintos grados de integración a diferentes sectores de la sociedad, a ámbitos y espacios de la ciudad. Y en esto desempeñan un papel importante la edad, 
el género, la educación, el trabajo, la economía, la nostalgia, el (des)arraigo, la cultura, así como la misma experiencia migratoria.

La utilización de las redes sociales y familiares en la ciudad de Mazatlán permite entender la solidaridad, la convivencia y las estrategias de supervivencia de las cuatro familias desplazadas, porque estas tienen una mayor posibilidad de superar algunas necesidades o mejorar sus condiciones de vida. Asimismo, en esta fase de la vida en la ciudad, las redes vienen a cubrir o a sustituir, casi por completo, la ayuda de las autoridades.

Por último, las autoridades municipal y estatal hacen esfuerzos por apoyar a los desplazados por la violencia y la inseguridad; sin embargo, esta ayuda ha tenido un carácter, principalmente asistencialista (entrega de despensas y cobijas, brigadas de salud), pero no constante, acción que no resuelve la problemática de fondo. Ayudaría más si a las familias desplazadas, se les brindara, además, trabajo, vivienda o refugio, salud y educación, mientras se les garanticen la seguridad y los derechos humanos, y también en espera de que se les restablezcan sus condiciones de vida donde ellos elijan.

\section{LISTA DE REFERENCIAS}

Albuja, S. et al. (2014). Global Overview 2014. People internally displaced by conflict and violence. Internal Displacement Monitoring Centre y Norwegian Refugee Council. Recuperado de http://www.internal-displacement.org/assets/publications/2014/201405-global-overview-2014-en.pdf

Arredondo, V. (septiembre, 2019). Se compra terreno para viviendas de desplazados. TVP. Recuperado de https://tvpacifico.mx/noticias/237254-se-compra-terreno-para-viviendas-de-desplazados-madrid?fbclid=IwAR3y3yUPhRCDM5YhGSJTyM42jeRtob37DOj1sMBXqJXTc-bOYKnFippXAfA

Bilak, A. et al. (2017). Global report on internal displacement GRID 2017. Internal Displacement Monitoring Centre, Norwegian Refugee Council. Ginebra, Suiza. Recuperado de http://www.internal-displacement.org/global-report/grid2017/ pdfs/2017-GRID.pdf

Bilak, A. et al. (2015). Global Overview 2015. People internally displaced by conflict and violence. Norwegian Refugee Council, Internal Displacement Monitoring Centre. Ginebra, Suiza. Recuperado de http://internal-displacement.org/assets/library/ Media/201505-Global-Overview-2015/20150506-global-overview-2015-en.pdf 
Bilak, A. et al. (2019). Global report on internal displacement GRID 2019. Internal Displacement Monitoring Centre, Norwegian Refugee Council. Ginebra, Suiza. Recuperado de http://www.internal-displacement.org/sites/default/files/publications/ documents/2019-IDMC-GRID.pdf

Cañedo, S. (2012). La reconstrucción de la identidad socioterritorial tras el desplazamiento provocado por la presa Picachos. El caso del Nuevo San Marcos. (Tesis de maestría). Facultad de Ciencias Sociales-Universidad Autónoma de Sinaloa, México.

Cañedo S., Vizcarra, M. y Arias, S. (2019). Desplazados por el yugo narco-minero en Sinaloa. Noroeste/Connectas. Plataforma Periodística para las Américas. Recuperado de https://www.connectas.org/especiales/desplazados-por-yugo-narcominero-sinaloa/

Castles, S. (2003). La política internacional de la migración forzada. Migración y Desarrollo, 1, 74-90. Red Internacional de Migración y Desarrollo. Recuperado de http://rimd.reduaz.mx/revista/rev1/StephenCastles.pdf

Desai, B., Ginnetti, J., Sémnani, S. y Anzellini, V. (2018). Global report on internal displacement GRID 2018. Internal Displacement Monitoring Centre, Norwegian Refugee Council. Ginebra, Suiza. Recuperado de http://www.internal-displacement. org/publications/2018-global-report-on-internal-displacement

Gutiérrez, R. (20 de noviembre, 2018). La traición de "el chapo" que acabó con los Beltrán Leyva. La Silla Rota. Recuperado de https://lasillarota.com/la-traicion-deel-chapo-que-acabo-con-los-beltran-leyva/258385

Harvey, D. (2005). El “nuevo" imperialismo: acumulación por desposesión. Buenos Aires, Argentina: Consejo Latinoamericano de Ciencias Sociales.

Internal Displacement Monitoring Centre y Norwegian Refugee Council (2011). México: desplazamiento debido a violencia criminal y comunal. Suiza. Recuperado de http://www.internal-displacement.org/assets/library/Americas/Mexico/pdf/ Mexico-November-2011.pdf

Lizárraga, A. (2002). Me agarró la ventolera... El proceso de la migración rural al extranjero en Sinaloa. Los casos de Cosalá, San Ignacio y El Verde. (Tesis doctoral). Centro de Investigaciones y Estudios Superiores en Antropología Social-Occidente/Centro Universitario de Ciencias Sociales y Humanidades-Universidad de Guadalajara, México.

Lizárraga, A. (2004). Nos llevó la ventolera... El proceso de la emigración rural al extranjero en Sinaloa. Los casos de Cosalá, San Ignacio y El Verde. México: Universidad Autónoma de Sinaloa.

Lizárraga, A. (2016). Sinaloa: Acumulación de capital por desposesión. Viva el Estado neoliberal. Ponencia presentada en precongreso 2017 de la Asociación Mexicana de 
Estudios Rurales, Desarrollo, Disputas Socioterritoriales y Violencia en el Medio Rural, y Cuarto Seminario Internacional del Centro de Estudios para el Desarrollo Económico y Social, de la Benemérita Universidad Autónoma de Puebla.

López R. (2012). Efectos de la violencia en el proceso migratorio del municipio de Tecuala, Nayarit (ejidos de San Felipe Aztatán y Quimichis). (Tesis de maestría). Facultad de Ciencias Sociales-Universidad Autónoma de Sinaloa, México.

López, R. (2017). Experiencias de emigración forzada de familias por la violencia en Sinaloa 2006-2016. Desplazamiento interno e integración social. (Tesis de doctorado). Universidad Autónoma de Sinaloa, México.

Márquez, H. y Delgado, R. (2011). Una perspectiva del sur sobre capital global, migración forzada y desarrollo alternativo. Migración y Desarrollo, 9(16), 3-42. Red Internacional de Migración y Desarrollo. Recuperado de http://www.redalyc.org/ articulo.oa? $\mathrm{id}=66021591001$

Mayer, P. (1963). Townsmen or tribesmen, urbanization in a divided society. Ciudad del Cabo: Oxford University Press.

Mestries, F. (2014). Los desplazados internos forzados: refugiados invisibles en su propia patria. El Cotidiano, 183, 17-25. Recuperado de http://www.redalyc.org/articulo.oa?id=32529943003

Meza S., Cuamea F. y Brito L. (18 de septiembre de 2014). Los nuevos dueños de la tierra. Los desplazados de la Sierra Madre (Segunda parte de tres partes). Noroeste. Recuperado de https://www.connectas.org/wp-content/uploads/2015/02/ SilberMeza-Desplazados2.pdf

Pérez, B., Bachi, D., Barbosa, L. y Castillo, M. (2019). Episodios de desplazamiento interno forzado masivo en México. Informe 2018. México: Comisión Mexicana de Defensa y Promoción de los Derechos Humanos, A. C. Recuperado de http:// www.cmdpdh.org/publicaciones-pdf/cmdpdh-episodios-de-desplazamiento-interno-forzado-en-mexico-informe-2018.pdf

Reynolds, S. (julio de 2014). Las víctimas ocultas de México. Refugees international, field report. Washington, D. C. Recuperado de http://www.refugeesinternational. org/sites/default/files/070214\%20Mexico\%20Unseen\%20Victims\%20Spanish\%20 letterhead.pdf

Salazar, L. M. y Castro, J. M. (2014). Tres dimensiones del desplazamiento interno forzado en México. El Cotidiano, 183, 57-66. Recuperado de http://www.redalyc. org/articulo.oa?id=32529943008 